Article

\title{
Achieving Economically Sustainable Subcontracting through the Hotelling Model by Considering the Spillover Effect
}

\author{
Jianbo Zhu ${ }^{1,2}$, Qianqian Shi ${ }^{1,3}{ }^{\oplus}$, Peng Wu ${ }^{2, *}$, Zhaohan Sheng ${ }^{1}$ and Xiangyu Wang ${ }^{4,5}$ \\ 1 School of Management and Engineering, Nanjing University, Nanjing 210093, China; \\ zhujianbowss@163.com (J.Z.); qqs1991@126.com (Q.S.); zhsheng@nju.edu.cn (Z.S.) \\ 2 School of Design and the Built Environment, Curtin University, Bentley, WA 6102, Australia \\ 3 Faculty of Civil Engineering and Geosciences, Delft University of Technology, Stevinweg 1, 2628 CN Delft, \\ The Netherlands \\ 4 School of Mathematical Sciences, Chongqing Normal University, Chongqing 400700, China; \\ xiangyu.wang@curtin.edu.au \\ 5 Department of Housing and Interior Design, Kyung Hee University, Seoul 02447, Korea \\ * Correspondence: peng.wu@curtin.edu.au; Tel.: +61-8-9266-4723
}

Received: 13 August 2018; Accepted: 10 September 2018; Published: 14 September 2018

check for updates

\begin{abstract}
In the process of internationalization of construction contractors, international enterprises as main contractors (IMC) need to consider whether part of the contract should be subcontracted to local subcontractors (LSC) to gain a competitive advantage when competing with local main contractors (LMC). The involvement of local subcontractors can usually help reduce cost through the cost spillover effect. However, it should be noted that the share of local subcontractors with local main contractors with an inferior quality may lead to quality spillover. The Hotelling model is therefore adopted to investigate the subcontracting decisions of main contractors considering both cost and quality spillover effects. Many scenarios are simulated and the results show that LMCs with inferior quality can always choose the subcontracting strategy to obtain increased profit regardless of the strategy that IMCs adopt. On the other hand, IMCs need to balance the cost spillover of subcontracting and the quality spillover for improving the quality level of LSCs. The results are useful for contractors to make decisions that are relevant to the adoption of subcontracting strategies to obtain competitive advantages.
\end{abstract}

Keywords: spillover effect; subcontracting; decision making; hotelling model; internationalization

\section{Introduction}

International outsourcing is a cooperation mechanism between enterprises in different countries or regions. In the process of global supply chain integration, the advantages of different countries, such as manpower, technology, knowledge, and energy, can be effectively integrated to reduce costs and increase efficiency. As a special type of commodity, infrastructure projects require the integration of resources to achieve expected project outcomes. According to Du et al. [1], partnering with local suppliers and subcontractors can help secure governments' approval and address local residents' concerns. Wang et al. [2] also found that using local or shared suppliers can enhance supplier reliability, which is often more important than cost. Therefore, selecting subcontractors is a common problem that needs to be solved by international contractors.

At the same time, we have noticed that such a trend has occurred in the construction of mega projects, and it is increasingly inclined to use factory prefabricated methods for manufacturing. For example, the steel box girder of the Hong Kong-Zhuhai-Macao Bridge is prefabricated in several 
production bases which are distributed throughout China. After prefabrication and centralized splicing, large-segment installations are carried out on site. In such a scenario, cooperation and competition often coexist [3,4]. Factory prefabrication is an environmentally friendly way of building, avoiding a large number of on-site construction, and then producing in a factory environment. It has been successfully applied in an increasing number of projects. It is one of the important ways in which the construction industry can achieve sustainability. With the prevalence of prefabricated and modular buildings, the construction of mega projects has also moved forward to the factory, allowing owners to make purchasing decisions with a broader perspective, including contractor selection in a larger space with the consideration of shipping length, time, and risk. When international contractors enter the local market, localized subcontracting is also an important way to reduce costs and resolve risks. Local subcontracting is also a double-edged sword. On one hand, it reduces costs and on the other hand, it also causes knowledge spillover, such as the development of high-speed rail technology in globalization. Therefore, adopting a conservative strategy to better protect corporate intellectual property rights, or adopting an expansion strategy to minimize costs and obtain economic benefits is a sustainable consideration for international business operations. Therefore, for international prefabrication contractors, what kind of strategy is adopted to compete with local contractors for price competition, and whether it is necessary to subcontract the contract locally are both important decisions that need to be prudent.

Due to the importance of selecting subcontractors in construction projects, subcontracting-related issues are common research problems in construction research. One of the most important problems is subcontractor selection (SCS). Most SCS-related studies focus on the development of appropriate decision support systems [5] and the application of internet technologies to assist the selection of subcontractors [6]. The most commonly adopted methods in subcontractor selection include fuzzy preferences to establish a comprehensive model [7], continuous ant colony and fuzzy set theory [8], and computer-supported systems to reduce the disadvantages of a single method [9]. The evaluation of subcontractors has also attracted significant attention. Some notable developments related to the evaluation of subcontractors include identifying key performance indicators for subcontractors $[10,11]$, testing the relative importance of evaluation elements, and establishing or developing relevant evaluation frameworks $[12,13]$. Other studies focus on the study of cooperatives relationships among contractors, including testing the relationship between fairness preferences or relationship value and subcontractors' willingness to cooperate [14], which are the key determinants of trust between main contractors and subcontractors [15], and the effects of creating an engineering culture to improve system capabilities [16].

Previous studies mainly focus on the general issues of selecting and evaluating subcontractors. However, specific considerations of the local environment are not usually included. As Ulubeyli and Kazaz [7] pointed out, if international contractors do not have experience in undertaking projects in the host country, they may face various risk types when conducting business. Therefore, seeking local and qualified subcontractors becomes an important way to reduce risks and increase profits [17]. Generally, subcontracting is needed when main contractors do not have the necessary production capacity, or have the production capacity but choose to subcontract because of the potential benefits of involving a local subcontractor. In the second scenario, the main contractors have to evaluate the scope of the work to be subcontracted before a selection decision can be made. However, many studies on supplier selection do not consider such differences. For example, Jadidi et al. [18] proposed a multi-objective optimization model for supplier selection based on three criteria, namely price, rejects, and lead-time. Kannan et al. [19] developed a fuzzy axiomatic design approach to help identify and select appropriate green suppliers. These studies are supplier-oriented, indicating the proposed models and methods are simply developed to evaluate the competency of suppliers.

However, if the main contractors have the production capacity and choose to invest in local suppliers, a quality/knowledge spillover will occur and may benefit local suppliers, which can sometimes be a threat to the main contractors as the competition level increases [20]. As such, 
the impact of the spillover cannot be overlooked when selecting local suppliers. The Hotelling model is a commonly adopted approach when buyers' preferences are considered in a duopoly market. The duopoly market is a simplified scenario and can be referred to when analyzing a more complicated oligopoly market. In addition, the Hotelling model has the benefits of providing accurate price equilibrium and is therefore ideal to evaluate the economic implications of subcontracting.

Given these issues, the situation considered in this paper is a linear distribution of owners, which is consistent with the linear urban distribution assumed by the Hotelling model. For bridge projects, it is often distributed along rivers or coastlines, showing typical linear characteristics. For example, some large-quality components such as steel box girder transportation and land transportation are often not economically viable, and contractors are often distributed on river banks or coasts. When selecting a site, contractors often choose to stay away from each other to avoid fierce competition in the same area. Therefore, we continue to consider a shared upstream supplier, and cooperation with such subcontractors will reduce costs, and international contractors will also lead to quality spillover effects through the intermediary role of this subcontractor. Such considerations have not been seen in the current research of the Hotelling model. Under such circumstances, international contractors need to balance the dual benefits of cost reduction and quality spillovers to make optimal decisions.

In the Hotelling model, owners' positions are linearly distributed, and international main contractors (IMC) and local main contractors (LMC) are located in a position on the linear line. Owners will choose the main contractor based on the principle of maximizing their own utility. This paper therefore aims to: (1) Analyze the competition between IMC and LMC using the Hotelling model; and (2) provide useful recommendations for selecting local suppliers while considering the spillover effect.

This paper is presented in the following structure. Section 2 reviews the previous studies on the spillover effect and modelling techniques. Section 3 presents the mathematical representations of the Hotelling model. Sections 4-6 present the implementation of the Hotelling model in various scenarios related to the adoption of subcontracting. A numerical simulation of the results is provided in Sections 7 and 8 concludes the study.

\section{Literature Review}

Spillover effect is considered as a consequence of knowledge or productivity transfer [21]. While outsourcing can bring positive benefits to collaborative parties, the spillover effect has a mixed impact on the cooperation between the two parties. In the cooperation, as Dussauge et al. [22] pointed out, it is difficult for participants to control the boundary of knowledge investment. Hsuan and Mahnke [23] argued that the investment in outsourcing can lead to knowledge spillover, thereby reducing the advantages of the investor, especially when the selected supplier is a shared one.

Many studies are therefore conducted on how the spillover effect can impact supplier selection. Qi et al. [24] found that when considering two competing companies investing in shared suppliers, the spillover effect will increase competition and can hinder business investment. Kang et al. [25] examined the effects of knowledge spillovers and reputation spillovers in OEM (original equipment manufacturer) suppliers in Taiwan and found that knowledge and reputation spillover can generally bring benefits to the suppliers. However, the suppliers' actions towards economic gain may lead to knowledge leakage, forcing the main contractors to implement more strict control. Similarly, in this paper, international contractors choose to enter the local market, which has certain technical advantages. This ensures that it can provide better quality than local contractors. The two contractors in a competitive relationship do not have a large amount of interaction, which leads to the overflow of knowledge, and once they choose to subcontract to the same upstream subcontractor, this situation will be reversed. As Kang et al. [25] pointed out in the literature, investments in shared suppliers can have positive inter-project spillover effect, while Qi et al. [24] indicated that as the ability of shared suppliers is improved, market competition will be further aggravated. In this paper, considering the sharing of 
the same upstream subcontractor, the quality improvement caused by the spillover of knowledge and technology is called "quality spillover".

For infrastructure projects, such as highways and tunnels, local construction standards are usually adopted and the designs of the main functions and contents of the projects are mainly done by the design organizations. The products provided by construction companies should help address the various requirements during the life cycle of the projects [26]. What the contractors essentially provide are normally considered as homogeneous construction products.

Hotelling [27] proposed the concept of transportation costs, pointing out that product pricing includes costs and transportation costs of customers, and the Hotelling model has then become a classic tool for analyzing product differentiation. Hotelling's competition model is widely used in product pricing and location selection decisions, as the location of the building has an important effect on the utility of the building [28]. The model has also been used to decide technical locations for specialized recycling processors in eco-industry parks [29], to analyze the long-term effects of the European gas market on the rising gas prices in Russia [30], and to investigate the impact on space competition of physical stores when joining online shops to supply external goods [31]. Recently, two studies are identified to use the Hotelling model to investigate the supply chain structure. Liu and Tyagi [32] used the Hotelling model to study the upward-decentralized supply chain structure and proposed the theory of strategic benefits, finding that while upstream businesses have no cost advantage, downstream businesses can still benefit from upward channel's decentralization. In addition, Hara and Matsubayashi [33] used the Hotelling model to analyze the relationship between retailer and manufacturer and studied the decision of introducing premium store brands. The above two articles use the Hotelling model to explore the two-tier structure of the supply chain, one is the subcontracting with homogenized products, and the other is the issue between manufacturers and retailers. This paper considers a two-tier supply chain structure close to their research, but further adds the considerations that both of the main contractors' upstream subcontractors are the same one [24], and quality spillover effect will occur. This study, therefore, aims to use the Hotelling model to analyze the subcontracting decisions between two main contractors (local and international) and that competitive advantages can be obtained in various scenarios when the two main contractors cooperate with the same subcontractor.

\section{Basic Model Assumptions}

It is assumed the subcontracting decision-making of the main contractors is based on the Hotelling model. This article only considers mega projects with linear distribution characteristics, typically such as bridge engineering. Considering the cost and convenience of transportation, steel structure contractors of a bridge are often distributed along rivers or coastlines, and transportation costs have become one of the important factors considered by owners. Based on the model, the following assumptions are necessary:

1. The location of the owner is linear and evenly distributed on the Hotelling line with a length of 1. The reservation unity $u$ of the owner should be large enough to ensure that the owners are interested in purchasing the products. The disutility of the owner is derived from the distance from the contractor's location. When the owner located at $x$ purchases the products from the contractor, he will gain the utility of:

$$
U_{0}=\mathrm{u}+\theta q_{i}-p_{i}-t\left(x-x_{i}\right)^{2}
$$

where: $U_{0}$ refers to the owner's total utility; $\theta$ refers to owner's utility coefficient related to different quality level of the main contractor; $q_{i}$ refers to the quality level that exceeds the contract requirement of the main contractor $i ; p_{i}$ is the price of the main contractor $i ; x_{i}$ refers to the position of the main contractor $i$ on the Hotelling line; $\theta q_{i}$ is the utility perception brought by different qualities, here it refers to the quality requirements achieved on the basis of the contract, such as the accuracy of the steel structure, the quality of the weld, the qualification rate of the 
metal flaw detection, etc.; $-t\left(x-x_{i}\right)^{2}$ is the disutility cost and $\mathrm{t}$ is the coefficient of disutility, As $\mathrm{d}$ 'Aspremont and Gabszewic [34] pointed out, if the disutility function is linear, the equalization may not exist; the quadratic function is relatively simple, which can facilitate the formation of equilibrium, and reflect the transportation risk increases with distance and time, resulting in a nonlinear relationship of negative effects. In addition, when both the two main contractors cooperate with the same subcontractor, as IMC has a relatively higher quality level, LMC can obtain an increase in the quality level of $\alpha \Delta \mathrm{q}(0 \leq \alpha \leq 1)$ (hereinafter referred to as quality spillover effect).

2. It is assumed there is competition between LMC and IMC. The position of the main contractor lies in $x_{i}$ of the Hotelling line. LMC is located on the left side of IMC on the Hotelling line (i.e., $x_{1}<x_{2}$ ), indicating that LMC has a relatively low quality level. It is also assumed that the costs of the two main contractors are both set as $c$ and neither of them has cost advantage [30].

3. It is also assumed there is an upstream LSC in the host country's construction market, and LMC and IMC both can cooperate with it. When the main contractors cooperate with the subcontractor, an extensive exchange of knowledge and technologies will occur between the main contractor and subcontractor, which will lead to a certain degree of cost spillover effect, where the production cost of the main contractor $i$ will be $\frac{c}{1+r_{i}} . r_{i}$ is the coefficient of the cost spillover effect. So, the profit of LMC is $E_{1}^{j}=\left(p_{1}-\frac{c}{1+r_{1}}\right) x^{*}$ in scenario $j$, and the profit of IMC is $E_{2}^{j}=\left(p_{2}-\frac{c}{1+r_{2}}\right)\left(1-x^{*}\right)$ in scenario $j$, here $x^{*}$ refers to the position of with the same residual value of the owner on the Hotelling line. As such, two types of spillover effect, including cost and quality, are considered in this study.

Table 1 presents a summary of the notations that will be used in the modelling process.

Table 1. Summary of notations.

\begin{tabular}{cl}
\hline Notations & Descriptions \\
\hline $\mathrm{u}$ & the reservation unity of the owner \\
$\theta$ & the owner's utility coefficient related to the main contractors' quality level \\
$q_{i}$ & the quality level of the main contractor $i$ \\
$\Delta \mathrm{q}$ & the quality difference between LMC and IMC \\
$p_{i}$ & the price set by of the main contractor $i$ \\
$t$ & the disutility coefficient of the owner \\
$x_{i}$ & the position of the main contractor $i$ on the Hotelling line \\
$x$ & the position of owner on the Hotelling line \\
$x^{*}$ & The position of with the same residual value of the owner on the Hotelling line \\
$c$ & the cost of the main contractor \\
$r_{i}$ & the coefficient of the cost spillover effect of the main contractor $i$ \\
$U_{0}$ & the utility of the owner \\
$\alpha$ & the coefficient of the quality spillover effect \\
$E_{i}^{j}$ & the profit of the main contractor $i$ in scenario $j$ \\
\hline
\end{tabular}

\section{Scenario 1: Both Main Contractors Adopt the Centralized Structure}

In order to investigate the various decision makings of IMCs and LMCs, a few scenarios will be investigated. As both IMC and LMC can make independent decisions on subcontracting, a total of four scenarios can be obtained, including: (1) Both contractors adopt the centralized structure; (2) only LMC adopts the decentralized structure; (3) only IMC adopts the decentralized structure; and (4) both contractors adopt the decentralized structure. It should be noted that in the last scenario when both contractors adopt the decentralized structure, both cost and quality spillover effects should be considered as the same subcontractor/supplier is shared. As such, a total of five scenarios will be investigated.

We firstly assume that both main contractors have adopted the centralized structure. In this case, all production services will take the form of self-provision rather than subcontracting. To study 
the impact of decentralized subcontract structure and spillover effect on the main contractor's decision-making, we use the centralized structure as a benchmark to compare contractors' profitability under different strategies.

The main contractors' position on the Hotelling line is fixed, and they have the right to price the product. According to their pricing, the owner can maximize his/her own residual value to make the decision. In other words, there is a point $x^{*}$ on the Hotelling line, which can satisfy the condition that the residual value of the two contractors should be the same. The formula is:

$$
\mathrm{u}+\theta q_{1}-p_{1}-t\left(x^{*}-x_{1}\right)^{2}=\mathrm{u}+\theta q_{2}-p_{2}-t\left(x^{*}-x_{2}\right)^{2}
$$

The owner with a preference on the left side of the point can purchase the products from the LMC. Similarly, the owner with a preference on the right side of the point can purchase the products from the IMC.

From Equation (2), the formula of calculating the position where the residual value of two contractors is:

$$
x^{*}=\frac{p_{2}-p_{1}-\theta \Delta \mathrm{q}}{2 t\left(x_{2}-x_{1}\right)}+\frac{x_{2}+x_{1}}{2}
$$

For ease of calculation, the difference in quality between the two contractors is set as $\Delta \mathrm{q}$. At this point, the profits of LMC and IMC can be calculated respectively as follows:

$$
\begin{gathered}
E_{1}=\left(p_{1}-c\right) x^{*} \\
E_{2}=\left(p_{2}-c\right)\left(1-x^{*}\right)
\end{gathered}
$$

The position with the same residual value of the owner is calculated by:

$$
x^{*}=\frac{x_{1}+x_{2}+2}{6}-\frac{\theta \Delta \mathrm{q}}{6 t\left(x_{2}-x_{1}\right)}
$$

The prices of LMC and IMC are respectively set as:

$$
\begin{aligned}
& p_{1}=\frac{t\left(x_{2}^{2}-x_{1}^{2}\right)+2 t\left(x_{2}-x_{1}\right)+3 c-\theta \Delta \mathrm{q}}{3} \\
& p_{2}=\frac{-t\left(x_{2}^{2}-x_{1}^{2}\right)+4 t\left(x_{2}-x_{1}\right)+3 c+\theta \Delta \mathrm{q}}{3}
\end{aligned}
$$

Given the prices and owner's position above, the profits of the LMC and IMC are, respectively:

$$
\begin{gathered}
E_{1}^{1}=\frac{\left[t\left(x_{2}^{2}-x_{1}^{2}\right)+2 t\left(x_{2}-x_{1}\right)-\theta \Delta \mathrm{q}\right]^{2}}{18 t\left(x_{2}-x_{1}\right)} \\
E_{2}^{1}=\frac{\left[-t\left(x_{2}^{2}-x_{1}^{2}\right)+4 t\left(x_{2}-x_{1}\right)+\theta \Delta \mathrm{q}\right]^{2}}{18 t\left(x_{2}-x_{1}\right)}
\end{gathered}
$$

\section{One Main Contractor Adopts the Decentralized Structure}

This section is concerned with the situation when one contractor uses the centralized structure and the other uses the decentralized structure. In this situation, the profit function of the main contractor using the centralized structure remains unchanged, while the main contractor choosing the decentralized structure will enjoy the spillover effect brought by cooperation with LSC. 


\subsection{Scenario 2: Only LMC Adopts the Decentralized Structure}

If LMC chooses to subcontract, the position with the same residual value of the owner is similar to that with the centralized structure (i.e., Equation (3)). LMC will benefit from the cost spillover effect. Specifically, cost will be reduced to a certain extent, determined by the degree of cooperation between the two enterprises. At this point, the profit of the enterprise with the decentralized structure is expressed as $E_{1}=\left(p_{1}-\frac{c}{1+r_{1}}\right) x^{*}$. The profit of the IMC with centralized structure is still expressed as $E_{2}=\left(p_{2}-\mathrm{c}\right)\left(1-x^{*}\right)$.

Therefore, if LMC chooses to subcontract and IMC does not, the prices of LMC and IMC are respectively set as:

$$
\begin{gathered}
p_{1}=\frac{t\left(x_{2}^{2}-x_{1}^{2}\right)+2 t\left(x_{2}-x_{1}\right)+c-\theta \Delta \mathrm{q}+\frac{2 c}{1+r_{1}}}{3} \\
p_{2}=\frac{-t\left(x_{2}^{2}-x_{1}^{2}\right)+4 t\left(x_{2}-x_{1}\right)+2 c+\theta \Delta \mathrm{q}+\frac{c}{1+r_{1}}}{3}
\end{gathered}
$$

The position of with the same residual value of the owner is calculated by:

$$
x^{*}=\frac{x_{1}+x_{2}+2}{6}-\frac{\theta \Delta \mathrm{q}-c+\frac{c}{1+r_{1}}}{6 t\left(x_{2}-x_{1}\right)}
$$

The profits of LMC and IMC are therefore:

$$
\begin{aligned}
& E_{1}^{2}=\frac{\left[t\left(x_{2}^{2}-x_{1}^{2}\right)+2 t\left(x_{2}-x_{1}\right)-\theta \Delta \mathrm{q}+\frac{c r_{1}}{1+r_{1}}\right]^{2}}{18 t\left(x_{2}-x_{1}\right)} \\
& E_{2}^{2}=\frac{\left[-t\left(x_{2}^{2}-x_{1}^{2}\right)+4 t\left(x_{2}-x_{1}\right)+\theta \Delta \mathrm{q}-\frac{c r_{1}}{1+r_{1}}\right]^{2}}{18 t\left(x_{2}-x_{1}\right)}
\end{aligned}
$$

When comparing the profits with the benchmark cases (i.e., Equations (9) and (10)), it is found that when LMC chooses to subcontract and IMC chooses a centralized strategy, the profit of LMC will increase and that of IMC will decrease.

From the price changes of the two main contractors, LMC has gained some cost advantage through the spillover effect through subcontracting (i.e., cost spillover effect). During competition, LMC can transform the cost advantage into a lower price, thus increasing the market share and occupying the market share of the IMC. The price of the LMC has decreased by $\Delta p_{11}=\frac{2 r_{1} c}{1+r_{1}}$ and similarly the price of IMC is decreased by $\Delta p_{21}=\frac{r_{1} c}{1+r_{1}}$. The position with the same residual value of the owner is moved to the right of the Hotelling line, indicating that the market share of LMC will increase and that of IMC will decrease. When compared with the benchmark case (Equation (6)), the difference is:

$$
\Delta x_{1}^{*}=\frac{c r_{1}}{6 t\left(x_{2}-x_{1}\right)\left(1+r_{1}\right)}
$$

In this scenario, the profit change of LMC will become:

$$
\Delta E_{11}=\frac{\left[2 t\left(x_{2}^{2}-x_{1}^{2}\right)+4 t\left(x_{2}-x_{1}\right)-2 \theta \Delta \mathrm{q}+\frac{c r_{1}}{1+r_{1}}\right] \frac{c r_{1}}{1+r_{1}}}{18 t\left(x_{2}-x_{1}\right)}>0
$$

The profit of IMC decreases by:

$$
\Delta E_{21}=-\frac{\left[-2 t\left(x_{2}^{2}-x_{1}^{2}\right)+8 t\left(x_{2}-x_{1}\right)+2 \theta \Delta \mathrm{q}-\frac{c r_{1}}{1+r_{1}}\right] \frac{c r_{1}}{1+r_{1}}}{18 t\left(x_{2}-x_{1}\right)}<0
$$


The increased value of the profit of LMC is higher than the decreased value of the profit of the IMC, as $\left|\Delta E_{1}\right|-\left|\Delta E_{2}\right|>0$. This means that the market has benefited from the subcontracting strategy of the LMC and the profit in the market has increased as a whole. As long as the cost spillover effect exists, it must be profitable for LMC to adopt the subcontracting strategy when the competing contractor adopts a centralized structure.

\subsection{Scenario 3: Only IMC Adopts the Decentralized Structure}

Similarly, when IMC adopts the subcontracting strategy, IMC will benefit from the cost spillover effect. The profit of LMC is expressed as $E_{1}=\left(p_{1}-c\right) x^{*}$. The profit of the IMC with centralized structure is still expressed as $E_{2}=\left(p_{2}-\frac{c}{1+r_{2}}\right)\left(1-x^{*}\right)$.

The prices of LMC and IMC are respectively set as:

$$
\begin{aligned}
& p_{1}=\frac{t\left(x_{2}^{2}-x_{1}^{2}\right)+2 t\left(x_{2}-x_{1}\right)-\theta \Delta \mathrm{q}+2 c+\frac{c}{1+r_{2}}}{3} \\
& p_{2}=\frac{-t\left(x_{2}^{2}-x_{1}^{2}\right)+4 t\left(x_{2}-x_{1}\right)+c+\theta \Delta \mathrm{q}+\frac{2 c}{1+r_{2}}}{3}
\end{aligned}
$$

The position with the same residual value of the owner is calculated by:

$$
x^{*}=\frac{x_{1}+x_{2}+2}{6}-\frac{\theta \Delta \mathrm{q}+c-\frac{c}{1+r_{2}}}{6 t\left(x_{2}-x_{1}\right)}
$$

As a result, the profits of LMC and IMC are:

$$
\begin{aligned}
& E_{1}^{3}=\frac{\left[t\left(x_{2}^{2}-x_{1}^{2}\right)+2 t\left(x_{2}-x_{1}\right)-\theta \Delta \mathrm{q}-\frac{c r_{2}}{1+r_{2}}\right]^{2}}{18 t\left(x_{2}-x_{1}\right)} \\
& E_{2}^{3}=\frac{\left[-t\left(x_{2}^{2}-x_{1}^{2}\right)+4 t\left(x_{2}-x_{1}\right)+\theta \Delta \mathrm{q}+\frac{c r_{2}}{1+r_{2}}\right]^{2}}{18 t\left(x_{2}-x_{1}\right)}
\end{aligned}
$$

When compared with the benchmark case (Equations (7) and (8)), it is found that as the cost of IMC decreases, because of the cost spillover effect, both main contractors can adopt a price reduction strategy. The price of LMC decreases by $\Delta p_{12}=\frac{c r_{2}}{3\left(1+r_{2}\right)}$, while the price of IMC will decrease by $\Delta p_{22}=\frac{2 c r_{2}}{3\left(1+r_{2}\right)}$.

In this scenario, compared with the benchmark case (Equations (9) and (10)), the profit change of LMC will become:

$$
\Delta E_{12}=-\frac{\left[2 t\left(x_{2}^{2}-x_{1}^{2}\right)+4 t\left(x_{2}-x_{1}\right)-2 \theta \Delta \mathrm{q}-\frac{c r_{2}}{1+r_{2}}\right] \frac{c r_{2}}{1+r_{2}}}{18 t\left(x_{2}-x_{1}\right)}<0
$$

Similarly, the profit change of IMC will become:

$$
\Delta E_{22}=\frac{\left[-2 t\left(x_{2}^{2}-x_{1}^{2}\right)+8 t\left(x_{2}-x_{1}\right)+2 \theta \Delta \mathrm{q}+\frac{c r_{2}}{1+r_{2}}\right] \frac{c r_{2}}{1+r_{2}}}{18 t\left(x_{2}-x_{1}\right)}>0
$$

As $\left|\Delta E_{22}\right|-\left|\Delta E_{12}\right|>0$, it can also be concluded that the market, as a whole, will benefit if IMC adopts the subcontracting strategy.

From these solutions, some important implications can be obtained. 
Proposition 1. Local main contractors can adopt the subcontracting strategy to increase profit when international main contractors choose a centralized structure. The overall market will benefit in terms of increased profit.

$$
\text { Confirmation: }\left|E_{1}^{2}\right|-\left|E_{1}^{1}\right|>0,\left|E_{2}^{2}\right|-\left|E_{2}^{1}\right|<0,|| E_{1}^{2}|-| E_{1}^{1}||-|| E_{2}^{2}|-| E_{2}^{1}||>0 \text {. }
$$

Proposition 2. International main contractors can adopt the subcontracting strategy to increase profit when local main contractors choose a centralized structure. The overall market will benefit in terms of increased profit.

$$
\text { Confirmation: }\left|E_{1}^{3}\right|-\left|E_{1}^{1}\right|<0,\left|E_{2}^{3}\right|-\left|E_{2}^{1}\right|>0,|| E_{2}^{3}|-| E_{2}^{1}||-|| E_{1}^{3}|-| E_{1}^{1}||>0 \text {. }
$$

\section{Both Contractors Adopt the Decentralized Strategy}

A situation where both main contractors adopt the decentralized subcontracting strategy is then investigated. In this situation, IMC and LMC have a subcontracting relationship with a LSC. The cost spillover effect is modelled, followed by the modelling of the quality spillover effect. For simplicity, we assumed the coefficient of the spillover effect is consistent.

\subsection{Scenario 4: Decentralized Strategy only Considering Cost Spillover Effect}

The two main contractors will benefit from the cost spillover effect. The profit of LMC is $E_{1}=$ $\left(p_{1}-\frac{c}{1+r_{1}}\right) x^{*}$ and the profit of IMC is $E_{2}=\left(p_{2}-\frac{c}{1+r_{2}}\right)\left(1-x^{*}\right)$.

By solving the Hotelling model, the prices of LMC and IMC are respectively set as:

$$
\begin{aligned}
& p_{1}=\frac{t\left(x_{2}^{2}-x_{1}^{2}\right)+2 t\left(x_{2}-x_{1}\right)-\theta \Delta \mathrm{q}+\frac{2 c}{1+r_{1}}+\frac{c}{1+r_{2}}}{3} \\
& p_{2}=\frac{-t\left(x_{2}^{2}-x_{1}^{2}\right)+4 t\left(x_{2}-x_{1}\right)+\theta \Delta \mathrm{q}+\frac{c}{1+r_{1}}+\frac{2 c}{1+r_{2}}}{3}
\end{aligned}
$$

The position of the same residual value of the owner is calculated by:

$$
x^{*}=\frac{x_{1}+x_{2}+2}{6}-\frac{\theta \Delta \mathrm{q}+\frac{c}{1+r_{1}}-\frac{c}{1+r_{2}}}{6 t\left(x_{2}-x_{1}\right)}
$$

The profits of LMC and IMC are therefore:

$$
\begin{gathered}
E_{1}^{4}=\frac{\left[t\left(x_{2}^{2}-x_{1}^{2}\right)+2 t\left(x_{2}-x_{1}\right)-\theta \Delta \mathrm{q}+\frac{c}{1+r_{2}}-\frac{c}{1+r_{1}}\right]^{2}}{18 t\left(x_{2}-x_{1}\right)} \\
E_{2}^{4}=\frac{\left[-t\left(x_{2}^{2}-x_{1}^{2}\right)+4 t\left(x_{2}-x_{1}\right)+\theta \Delta \mathrm{q}+\frac{c}{1+r_{1}}-\frac{c}{1+r_{2}}\right]^{2}}{18 t\left(x_{2}-x_{1}\right)}
\end{gathered}
$$

The position of the same residual value of the owner, price and profits of LMC and IMC are compared with the previous scenarios. The results are shown in Table 2. 
Table 2. The performance of LMC and IMC, when compared with the other three scenarios considering cost spillover effect.

\begin{tabular}{|c|c|c|c|}
\hline Indicators & Scenario 1 & Scenario 2 & Scenario 3 \\
\hline $\begin{array}{c}\text { The change of the position of } \\
\text { with the same residual value of } \\
\text { the owner } \Delta x^{*}\end{array}$ & $\frac{\frac{c}{1+r_{2}}-\frac{c}{1+r_{1}}}{6 t\left(x_{2}-x_{1}\right)}$ & $-\frac{\frac{r_{2} c}{1+r_{2}}}{6 t\left(x_{2}-x_{1}\right)}$ & $\frac{\frac{r_{1} c}{1+r_{1}}}{6 t\left(x_{2}-x_{1}\right)}$ \\
\hline Price change of LMC $\Delta p_{1}$ & $-\left(\frac{2 c r_{1}}{3\left(1+r_{1}\right)}+\frac{c r_{2}}{3\left(1+r_{2}\right)}\right)$ & $-\frac{c r_{2}}{3\left(1+r_{2}\right)}$ & $-\frac{2 c r_{1}}{3\left(1+r_{1}\right)}$ \\
\hline Price change of IMC $\Delta p_{2}$ & $-\left(\frac{c r_{1}}{3\left(1+r_{1}\right)}+\frac{2 c r_{2}}{3\left(1+r_{2}\right)}\right)$ & $-\frac{2 c r_{2}}{3\left(1+r_{2}\right)}$ & $-\frac{c r_{1}}{3\left(1+r_{1}\right)}$ \\
\hline Profit change of LMC $\Delta E_{1}$ & $\frac{\left(\mathrm{u}_{1}+\frac{c}{1+r_{2}}-\frac{c}{1+r_{1}}\right)\left(\frac{c}{1+r_{2}}-\frac{c}{1+r_{1}}\right)}{18 t\left(x_{2}-x_{1}\right)}$ & $\frac{\left[\mathrm{u}_{1}+\frac{c}{1+r_{2}}-\frac{c\left(1-r_{1}\right)}{1+r_{1}}\right]\left(\frac{c}{1+r_{2}}-c\right)}{18 t\left(x_{2}-x_{1}\right)}<0$ & $\frac{\left[\mathrm{u}_{1}+\frac{c\left(1-r_{2}\right)}{1+r_{2}}-\frac{c}{1+r_{1}}\right]\left(c-\frac{c}{1+r_{1}}\right)}{18 t\left(x_{2}-x_{1}\right)}>0$ \\
\hline Price change of IMC $\Delta E_{2}$ & $\frac{\left(\mathrm{u}_{2}+\frac{c}{1+r_{1}}-\frac{c}{1+r_{2}}\right)\left(\frac{c}{1+r_{1}}-\frac{c}{1+r_{2}}\right)}{18 t\left(x_{2}-x_{1}\right)}$ & $\frac{\left[\mathbf{u}_{2}-\frac{c}{1+r_{2}}+\frac{c\left(1-r_{1}\right)}{1+r_{1}}\right]\left(c-\frac{c}{1+r_{2}}\right)}{18 t\left(x_{2}-x_{1}\right)}>0$ & $\frac{\left[\mathrm{u}_{2}-\frac{c\left(1-r_{2}\right)}{1+r_{2}}+\frac{c}{1+r_{1}}\right]\left(\frac{c}{1+r_{1}}-c\right)}{18 t\left(x_{2}-x_{1}\right)}<0$ \\
\hline
\end{tabular}

Compared with Scenario 1 where both contractors adopt the centralized structure, both LMC and IMC will adopt a price reduction strategy. It is also found that the market share of LMC and IMC will also vary, depending on the change to the position with the same residual value of the owner. When $r_{1}=r_{2}$, such position remains unchanged, meaning that the market shares of LMC and IMC are unchanged. On the other hand, when $r_{1}>r_{2}$, such a position will move right on the Hotelling line, meaning that the market share of LMC increases and the profit of LMC increases while the profit of IMC decreases. When $r_{1}<r_{2}$, such a position will move left on the Hotelling line, indicating that the market share and profit of IMC increase while the market share and profit of LMC decrease.

Compared with Scenario 2 when only LMC adopts the decentralized strategy, the position with the same residual value of the owner moves towards left of the Hotelling line, indicating that IMC regains some market share through price reduction. This will also force LMC to further lower its price at half the value of the price reduction of IMC. As a result, the profit of LMC decreases and the profit of IMC increases.

Similarly, compared with Scenario 3 when only IMC adopts the decentralized strategy, the indifference position of the owner moves towards right of the Hotelling line, indicating that LMC regains some market share through price reduction. As a result, the profit of LMC increases and the profit of IMC decreases. A proposition can therefore be obtained based on the above discussion.

\subsection{Scenario 5: Decentralized Strategy Considering Cost Spillover Effect and Quality Spillover Effect}

During cooperation involving the same subcontractor, the contractor with the higher quality level will inevitably face the spillover of technology and knowledge, thus improving the production quality of the inferior contractor. It is assumed that the quality spillover effect can improve the production quality of the inferior contractor (which is assumed to be LMC) by a degree of $\alpha \Delta \mathrm{q}(0 \leq \alpha \leq 1)$.

The profit of LMC is $E_{1}=\left(p_{1}-\frac{c}{1+r_{1}}\right) x^{*}$ and the profit of IMC is $E_{2}=\left(p_{2}-\frac{c}{1+r_{2}}\right)\left(1-x^{*}\right)$.

By solving the Hotelling model, the prices of LMC and IMC are, respectively:

$$
\begin{aligned}
& p_{1}=\frac{t\left(x_{2}^{2}-x_{1}^{2}\right)+2 t\left(x_{2}-x_{1}\right)-\theta \Delta \mathrm{q}(1-\alpha)+\frac{2 c}{1+r_{1}}+\frac{c}{1+r_{2}}}{3} \\
& p_{2}=\frac{-t\left(x_{2}^{2}-x_{1}^{2}\right)+4 t\left(x_{2}-x_{1}\right)+\theta \Delta \mathrm{q}(1-\alpha)+\frac{c}{1+r_{1}}+\frac{2 c}{1+r_{2}}}{3}
\end{aligned}
$$

The position with the same residual value of the owner is:

$$
x^{*}=\frac{x_{1}+x_{2}+2}{6}-\frac{\theta \Delta \mathrm{q}(1-\alpha)+\frac{c}{1+r_{1}}-\frac{c}{1+r_{2}}}{6 t\left(x_{2}-x_{1}\right)}
$$


The profits of LMC and IMC are, respectively:

$$
\begin{aligned}
E_{1}^{5} & =\frac{\left[t\left(x_{2}^{2}-x_{1}^{2}\right)+2 t\left(x_{2}-x_{1}\right)-\theta \Delta \mathrm{q}(1-\alpha)+\frac{c}{1+r_{2}}-\frac{c}{1+r_{1}}\right]^{2}}{18 t\left(x_{2}-x_{1}\right)} \\
E_{2}^{5} & =\frac{\left[-t\left(x_{2}^{2}-x_{1}^{2}\right)+4 t\left(x_{2}-x_{1}\right)+\theta \Delta \mathrm{q}(1-\alpha)+\frac{c}{1+r_{1}}-\frac{c}{1+r_{2}}\right]^{2}}{18 t\left(x_{2}-x_{1}\right)}
\end{aligned}
$$

The market share, price and profits of the two contractors considering cost and quality spillover effect are compared with the same three scenarios. The results are shown in Table 3.

Mixed results are found when both cost and quality spillover effect are considered. Compared with Scenario 1 when both contractors do not adopt the subcontracting strategy, the prices of LMC and IMC decrease. However, whether the price reduction can lead to increased market share will be dependent on the magnitude of the quality and cost spillover effect. For example, when $\alpha \theta \Delta q>\frac{c}{1+r_{1}}-\frac{c}{1+r_{2}}$ (i.e., the benefit of quality spillover effect that LMC obtains exceeds the price difference of LMC and IMC considering the cost spillover effect), the position with the same residual value of the owner will move towards right of the Hotelling line, meaning that the market share LMC increases and that of IMC decreases. Consequently, the profit of LMC increases and that of IMC decreases.

Compared with Scenario 2 when only LMC adopts the subcontracting strategy, it is found that the market share, price and profit of the two contractors will be dependent on the magnitude of the quality spillover effect (i.e., $\alpha \theta \Delta q$ ) and the cost benefit that IMC obtains through the cost spillover effect (i.e., $\frac{r_{2} c}{1+r_{2}}$ ).

It is interesting to find that compared to Scenario 3 when only IMC adopts the subcontracting strategy, the adoption of subcontracting by LMC will always lead to increased market share and increased profit. The price change will be dependent on the magnitude of the quality spillover effect and the cost benefit that IMC obtains through the cost spillover effect (i.e., $\left.\frac{r_{1} c}{1+r_{1}}\right)$.

Some useful implications can therefore be obtained.

Proposition 3. Considering both cost and quality spillover effects, regardless of what strategy the international main contractor adopts, the local main contractor that has an inferior position can always choose the subcontracting strategy to obtain better profit.

Confirmation: $\left|E_{1}^{2}\right|-\left|E_{1}^{1}\right|>0,\left|E_{1}^{5}\right|-\left|E_{1}^{3}\right|>0$.

Proposition 4. Considering both cost and quality spillover effects, whether or not the international main contractor should choose the subcontracting strategy is dependent on the magnitude of the quality spillover effect and the coefficient of the cost spillover effect

When the quality spillover effect exceeds the cost benefit that can be obtained through the cost spillover effect (i.e.,) $\alpha>\frac{r_{2} c}{\theta \Delta \mathrm{q}\left(1+r_{2}\right)}$, the international contractor will always adopt the centralized strategy, as the adoption of a decentralized strategy can lead to reduced profit.

Confirmation: $\left|E_{2}^{5}\right|-\left|E_{2}^{2}\right|>0$.

When the quality spillover effect is below a certain level (i.e., $\alpha<\frac{r_{2} c}{\theta \Delta \mathrm{q}\left(1+r_{2}\right)}$ ), the international main contractor can adopt the decentralized strategy to increase profit.

Confirmation: $\left|E_{2}^{5}\right|-\left|E_{2}^{2}\right|<0$. 
Table 3. The performance of LMC and IMC, when compared with the other three scenarios considering cost and quality spillover effect.

\begin{tabular}{|c|c|c|c|}
\hline Indicators & Scenario 1 & Scenario 2 & Scenario 3 \\
\hline $\begin{array}{l}\text { The change of the position of with the } \\
\text { same residual value of the owner } \Delta x^{*}\end{array}$ & $\frac{\alpha \theta \Delta \mathrm{q}+\frac{c}{1+r_{2}}-\frac{c}{1+r_{1}}}{6 t\left(x_{2}-x_{1}\right)}$ & $\frac{\alpha \theta \Delta \mathrm{q}-\frac{r_{2} c}{1+r_{2}}}{6 t\left(x_{2}-x_{1}\right)}$ & $\frac{\alpha \theta \Delta \mathrm{q}+\frac{r_{1} c}{1+r_{1}}}{6 t\left(x_{2}-x_{1}\right)}>0$ \\
\hline Price change of LMC $\Delta p_{1}$ & $-\left(\frac{2 c r_{1}}{3\left(1+r_{1}\right)}+\frac{c r_{2}}{3\left(1+r_{2}\right)}-\frac{\alpha \theta \Delta q}{3}\right)$ & $-\left(\frac{c r_{2}}{3\left(1+r_{2}\right)}-\frac{\alpha \theta \Delta q}{3}\right)$ & $-\left(\frac{2 c r_{1}}{3\left(1+r_{1}\right)}-\frac{\alpha \theta \Delta q}{3}\right)$ \\
\hline Price change of IMC $\Delta p_{2}$ & $-\left(\frac{c r_{1}}{3\left(1+r_{1}\right)}+\frac{2 c r_{2}}{3\left(1+r_{2}\right)}+\frac{\alpha \theta \Delta q}{3}\right)<0$ & $-\left(\frac{2 c r_{2}}{3\left(1+r_{2}\right)}+\frac{\alpha \theta \Delta q}{3}\right)<0$ & $-\left(\frac{c r_{1}}{3\left(1+r_{1}\right)}+\frac{\alpha \theta \Delta q}{3}\right)<0$ \\
\hline Profit change of LMC $\Delta E_{1}$ & $\frac{\left(\mathrm{u}_{1}+\alpha \theta \Delta \mathrm{q}+\frac{c}{1+r_{2}}-\frac{c}{1+r_{1}}\right)\left(\alpha \theta \Delta \mathrm{q}+\frac{c}{1+r_{2}}-\frac{c}{1+r_{1}}\right)}{18 \mathrm{t}\left(x_{2}-x_{1}\right)}$ & $\frac{\left(\mathrm{u}_{1}+\alpha \theta \Delta \mathrm{q}+\frac{c}{1+r_{2}}-\frac{c\left(1-r_{1}\right)}{1+r_{1}}\right)\left(\alpha \theta \Delta \mathrm{q}-\frac{c r_{2}}{1+r_{2}}\right)}{18 t\left(x_{2}-x_{1}\right)}$ & $\frac{\left(u_{1}+\alpha \theta \Delta q+\frac{c\left(1-r_{2}\right)}{1+r_{2}}-\frac{c}{1+r_{1}}\right)\left(\alpha \theta \Delta q+\frac{c r_{1}}{1+r_{1}}\right)}{18 t\left(x_{2}-x_{1}\right)}>0$ \\
\hline Profit change of IMC $\Delta E_{2}$ & $\frac{\left(\mathrm{u}_{2}-\alpha \theta \Delta \mathrm{q}+\frac{c}{1+r_{1}}-\frac{c}{1+r_{2}}\right)\left(\frac{c}{1+r_{1}}-\frac{c}{1+r_{2}}-\alpha \theta \Delta \mathrm{q}\right)}{18 t\left(x_{2}-x_{1}\right)}$ & $\frac{\left(\mathrm{u}_{2}-\alpha \theta \Delta \mathrm{q}+\frac{c\left(1-r_{1}\right)}{1+r_{1}}-\frac{c}{1+r_{2}}\right)\left(\frac{c r_{2}}{1+r_{2}}-\alpha \theta \Delta \mathrm{q}\right)}{18 t\left(x_{2}-x_{1}\right)}$ & $\frac{\left(\mathrm{u}_{2}-\alpha \theta \Delta \mathrm{q}+\frac{c}{1+r_{1}}-\frac{c\left(1-r_{2}\right)}{1+r_{2}}\right)\left(-\alpha \theta \Delta \mathrm{q}-\frac{c r_{1}}{1+r_{1}}\right)}{18 t\left(x_{2}-x_{1}\right)}<0$ \\
\hline
\end{tabular}

Note: $2 t\left(x_{2}^{2}-x_{1}^{2}\right)+4 t\left(x_{2}-x_{1}\right)-2 \theta \Delta \mathrm{q}=\mathrm{u}_{1},-2 t\left(x_{2}^{2}-x_{1}^{2}\right)+8 t\left(x_{2}-x_{1}\right)+2 \theta \Delta \mathrm{q}=\mathrm{u}_{2}$. 


\section{Numerical Simulation}

A numerical simulation is conducted based on the above theoretical analysis to demonstrate the selection of the subcontracting strategy of LMC and IMC in various situations.

It is assumed that the coefficient of owner's disutility t equals to 100. In addition, LMC is located at the position of $x_{1}=0.1$ and IMC is located at the position of $x_{2}=0.8$. The cost spillover factors $r_{1}$ and $r_{2}$ vary from 0 to 5 in order to analyze the profit changes of LMC and IMC when their rivals choose different strategies. The numerical simulation results when only the cost spillover effect is considered are shown in Figures 1 and 2.
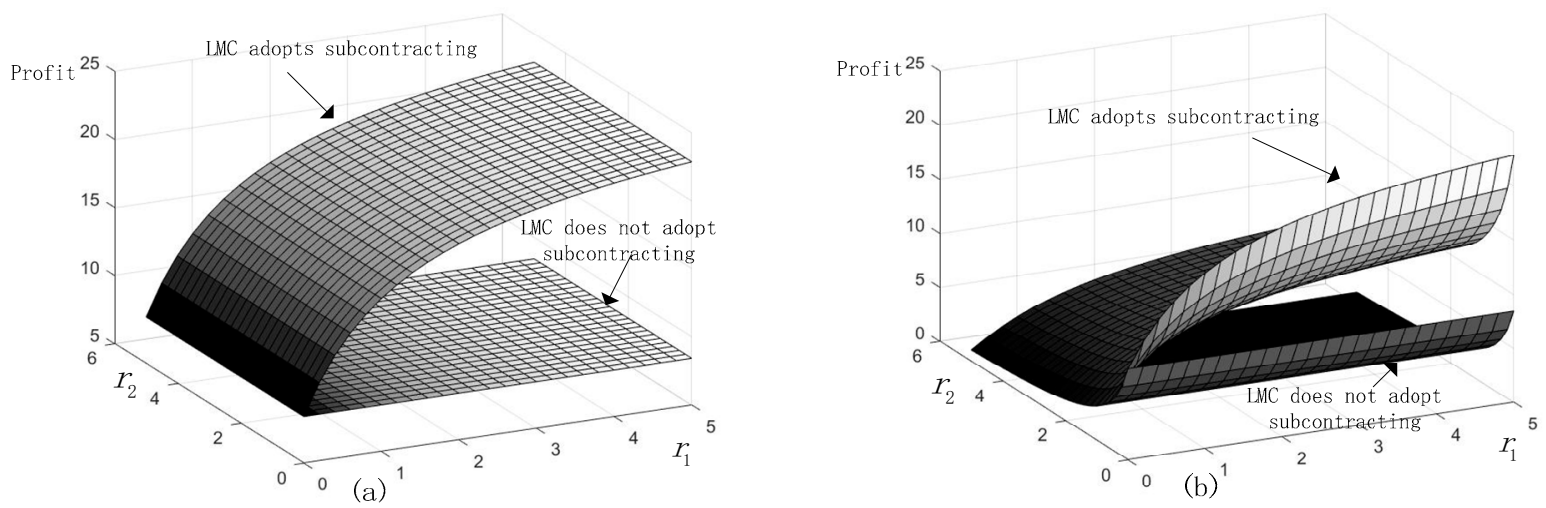

Figure 1. (a) LMC's profit when IMC does not adopt subcontracting; (b) LMC's profit when IMC adopts subcontracting.
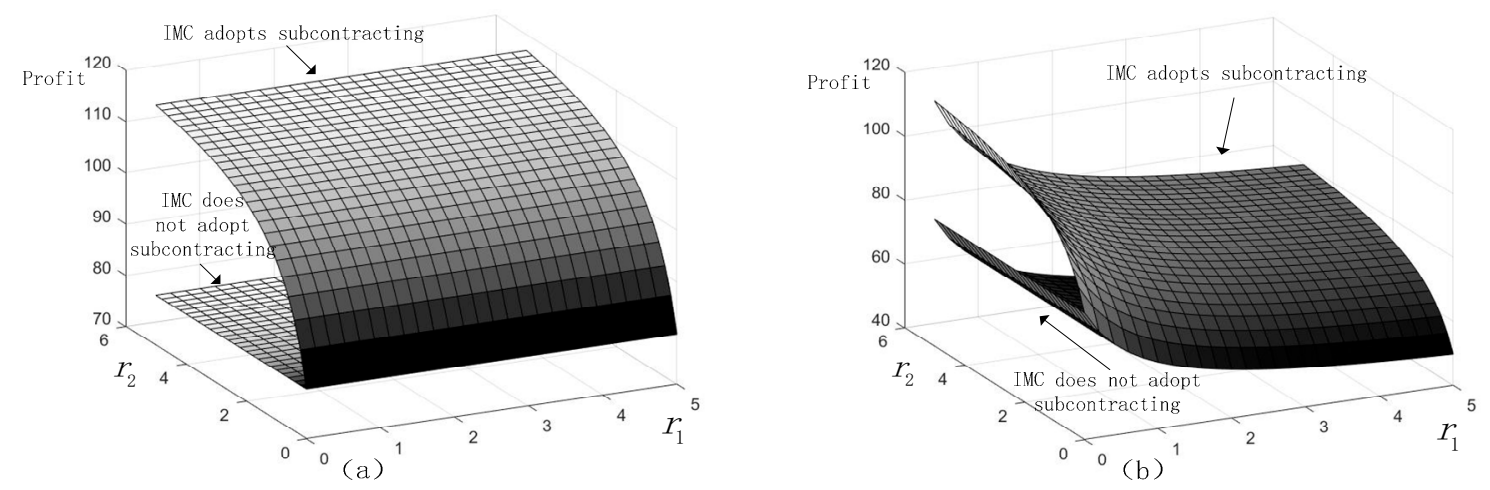

Figure 2. (a) IMC's profit when LMC does not adopt subcontracting; (b) IMC's profit when LMC adopts subcontracting.

Figure 1a shows the profit of LMC when it adopts the decentralized structure under the situation when IMC adopts the centralized strategy, i.e., without subcontracting. Figure $1 \mathrm{~b}$ shows the profit of LMC when it follows its competing contractor to adopt the subcontracting strategy. The simulation shows that as LMC can always adopt the subcontracting strategy to obtain better profits. In this first situation, the new increased profit is related to the coefficient of the cost spillover effect of LMC (Equation (14)). Comparatively, when IMC has already implemented the subcontracting strategy, LMC can still chose the decentralized strategy to obtain better profit. However, the new increased profit will be dependent on the coefficient of the cost spillover effects of both LMC and IMC (Equation (29)).

Similarly, Figure 2a,b show the profit of IMC when the competing contractor (i.e., LMC) adopts a centralized and decentralized structure. Figure 2a shows that IMC can always adopt the subcontracting strategy to increase profit when the competing contractor adopts a centralized structure. The new increased profit will be dependent on the coefficient of the cost spillover effect of IMC (Equation (23)). IMC can also adopt the subcontracting strategy to increase profit when LMC adopts the decentralized 
strategy. In this case, the new increased profit will be dependent on the coefficient of the cost spillover effects of both LMC and IMC (Equation (30)).

Figure 3 demonstrates the simulation results when both the cost and quality spillover effects are considered. The simulation results confirm that when the two types of spillover effects are considered, LMC who has an inferior position in terms of quality, can always adopt the subcontracting strategy to increase its project. When IMC does not adopt the subcontracting strategy, no quality spillover effect will occur. Figure 1a shows that LMC can adopt the subcontracting strategy to increase profit and the increased profit is only related to the coefficient of the cost spillover effect of LMC. On the other hand, when IMC has already adopted the subcontracting strategy, once LMC adopts the subcontracting strategy, quality spillover effect will occur. As can be seen from Figure 3, LMC can still adopt the subcontracting strategy to increase profit. The new increased profit is related to the coefficient of the cost spillover effects of LMC and IMC, as well as the magnitude of the quality spillover effect (Equation (33)). For simplicity, Figure 3 only shows the relationship between the new increased profit and the coefficient of cost spillover effect of IMC and the magnitude of the quality spillover effect.

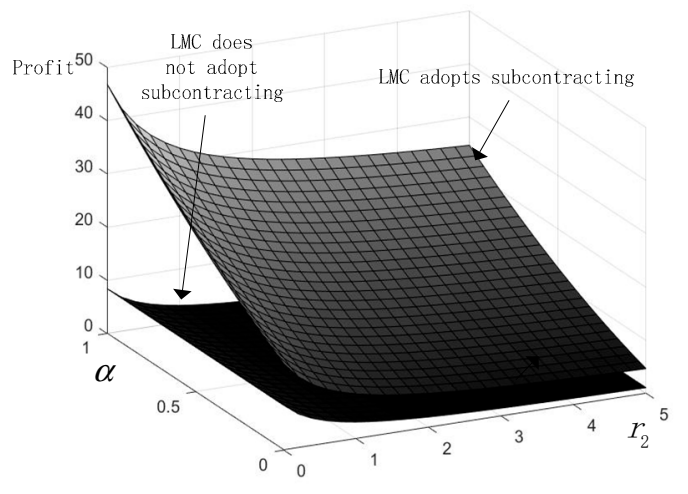

Figure 3. LMC's profit when IMC adopts subcontracting considering both cost and quality spillover effects.

On the other hand, when LMC has already adopted the subcontracting strategy, IMC's adoption of the subcontracting strategy may not bring increased profit. The new profit will be dependent on the coefficient of the cost spillover effect of LMC and IMC, as well as the magnitude of the quality spillover effect, as shown in Figure 4.

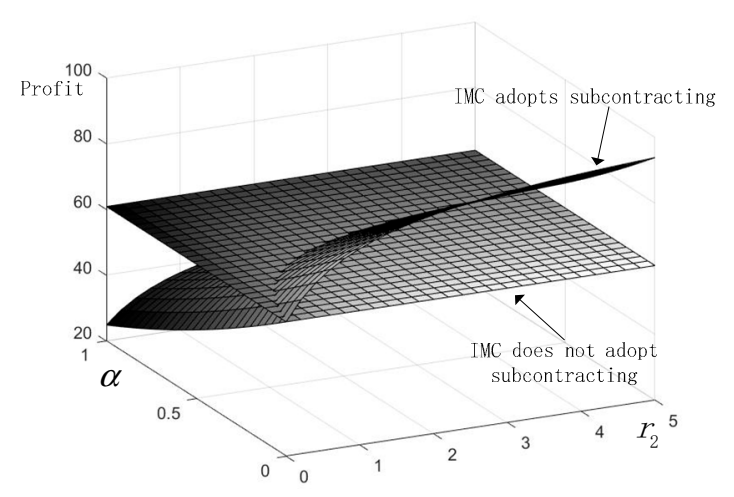

Figure 4. IMC's profit when LMC adopts subcontracting considering both cost and quality spillover effect.

Economic considerations when making subcontracting decisions are critical to the competitiveness of contractors [5]. As such, understanding the economic implications of subcontracting on contractors is important to achieve maximized benefits. Many studies have been conducted on investigating the equilibrium locations, transport costs and marginal costs of two key players when subcontracting is 
involved, i.e., the duopoly in the market $[35,36]$. This study contributes to the inclusion of quality level and two types of spillover effects in the competition. For example, it is found that the firm with lower marginal cost can always adopt the subcontracting strategy to obtain benefit [35]. In this study, it is found that the firm with the lower quality level can always adopt the subcontracting strategy to obtain benefit.

\section{Conclusions}

Subcontracting has become an important strategy for reducing cost and diversifying political and technological risks in the international construction market. During the subcontracting process, international contractors also face the risk of knowledge spillover, which may pose a threat to the core competitiveness of international contractors. It is therefore important to understand the consequences of subcontracting decisions for both international and local contractors.

Using the Hotelling model, this study concludes that a local contractor that has an inferior position can always adopt the subcontracting strategy to increase profit. This is independent of the subcontracting strategy that the international contractor adopts. On the other hand, while the decentralized structure can help international contractors gain a competitive advantage by lowering the cost, the adoption of such a structure may expose international contractors to the quality spillover, which can harm their profitability by improving the quality level of local contractors. Different from the conclusions of Liu and Rajeev [32], their findings show that a decentralized supply chain structure makes incentives more effective. Even if the upstream subcontractors have no cost advantage, such a decentralized structure can still benefit both parties. However, this paper considers that the upstream subcontractors are the same, which in turn leads to the consideration of quality spillover effects, thus forming an unfair competition environment, which is closer to reality and leads to the result of differentiation. A similar conclusion was obtained with Qi et al. [24], the higher spillover effect brought about an increase in market competition, and also hindered the investment in the shared supplier. Therefore, careful decisions of subcontracting should be made when international contractors intend to enter new markets with a high degree of quality spillover. Based on the relationship between the cost reduction coefficient and the spillover effect coefficient, this paper gives suggestions for the subcontract decision-making of international main contractors.

It should be noted that this study has a few limitations. The above conclusion is based on the assumption that a duopoly is modelled with the involvement of only one subcontractor. In a competitive market, the competition and subcontracting structure may be more complicated. In addition, it is assumed that all contractors are absolutely rational, meaning that they only focus on profit to make decisions. In reality, the decisions of contractors may be influenced by other factors, such as perception of fairness, political reasons, tax concessions or other forms of subsidies for local investments. These factors are recommended to be included in future studies.

Author Contributions: The manuscript was written through contributions of all authors. All authors have given approval to the final version of the manuscript.

Funding: This work is supported by Major Program of National Natural Science Foundation of China (71390520, 71390521), National Natural Science Foundation of China (71571098, 71732003, 71671088, 71671078, 71701090), Nanjing University Innovation and Creative Program for Ph.D. candidate (2016010), and the program A\&B for Outstanding Ph.D. candidate of Nanjing University (201801A001, 201701B009, 201701B010), and the Australian Government through the Australian Research Council's Discovery Project funding scheme (project DP180104026).

Conflicts of Interest: The authors declare no conflict of interest. 


\section{References}

1. Du, L.; Tang, W.; Liu, C.; Wang, S.; Wang, T.; Shen, W.; Huang, M.; Zhou, Y. Enhancing engineer-procure-construct project performance by partnering in international markets: Perspective from Chinese construction companies. Int. J. Proj. Manag. 2016, 34, 30-43. [CrossRef]

2. Yimin, W.; Xiao, Y.; Yang, N. Improving reliability of a shared supplier with competition and spillovers. Eur. J. Oper. Res. 2014, 236, 499-510.

3. Shi, Q.; Zhu, J.; Li, Q. Cooperative evolutionary game and applications in construction supplier tendency. Complexity 2018, 2018, 8401813. [CrossRef]

4. Zhu, J.; Shi, Q.; Wu, P.; Sheng, Z.; Wang, X. Complexity Analysis of Prefabrication Contractors' Dynamic Price Competition in Mega Projects with Different Competition Strategies. Complexity 2018, 2018, 5928235. [CrossRef]

5. Elazouni, A.M.; Metwally, F.G. D-SUB: Decision support system for subcontracting construction works. J. Constr. Eng. Manag. 2000, 126, 191-200. [CrossRef]

6. Arslan, G.; Kivrak, S.; Birgonul, M.T.; Dikmen, I. Improving sub-contractor selection process in construction projects: Web-based sub-contractor evaluation system (WEBSES). Autom. Constr. 2008, 17, 480-488. [CrossRef]

7. Hamidreza, A.; Rajaie, H.; Shakeri, E. A framework for subcontractor selection in the construction industry. J. Civ. Eng. Manag. 2013, 19, 158-168.

8. Abbasianjahromi, H.; Rajaie, H.; Shakeri, E.; Chokan, F. A new decision making model for subcontractor selection and its order allocation. Proj. Manag. J. 2014, 45, 55-66. [CrossRef]

9. Serdar, U.; Kazaz, A. Fuzzy multi-criteria decision making model for subcontractor selection in international construction projects. Technol. Econ. Dev. Econ. 2016, 22, 210-234.

10. Andreas, H.; Ling, F.Y.Y.; Tan, J.S.H. Relative importance of subcontractor selection criteria: Evidence from Singapore. J. Constr. Eng. Manag. 2009, 135, 826-832.

11. Thomas, N.S.; Luu, C.D.T. Modeling subcontractor registration decisions through case-based reasoning approach. Autom. Constr. 2008, 17, 873-881.

12. Mbachu, J. Conceptual framework for the assessment of subcontractors' eligibility and performance in the construction industry. Constr. Manag. Econ. 2008, 26, 471-484. [CrossRef]

13. Thomas, N.S.; Skitmore, M. Developing a framework for subcontractor appraisal using a balanced scorecard. J. Civ. Eng. Manag. 2014, 20, 149-158.

14. Liu, J.; Yang, P.; Xia, B.; Skitmore, M. Effect of Perceived Justice on Subcontractor Willingness to Cooperate: The Mediating Role of Relationship Value. J. Constr. Eng. Manag. 2017, 143, 04017062. [CrossRef]

15. Manu, E.; Ankrah, N.; Chinyio, E.; Proverbs, D. Trust influencing factors in main contractor and subcontractor relationships during projects. Int. J. Proj. Manag. 2015, 33, 1495-1508. [CrossRef]

16. Pia, O.; Gotcheva, N. Safety culture and subcontractor network governance in a complex safety critical project. Reliabil. Eng. Syst. Saf. 2015, 141, 106-114.

17. Suresh, M.; Agrawal, A. Does Quality Knowledge Spillover at Shared Suppliers? An Empirical Investigation. Manuf. Serv. Oper. Manag. 2016, 18, 525-544.

18. Omid, J.; Cavalieri, S.; Zolfaghari, S. An improved multi-choice goal programming approach for supplier selection problems. Appl. Math. Model. 2015, 39, 4213-4222.

19. Devika, K.; Govindan, K.; Rajendran, S. Fuzzy Axiomatic Design approach based green supplier selection: A case study from Singapore. J. Clean. Prod. 2015, 96, 194-208.

20. Kazuyuki, M.; Yuan, Y. Productivity impact of technology spillover from multinationals to local firms: Comparing China's automobile and electronics industries. Res. Policy 2010, 39, 790-798.

21. Isaksson, O.H.; Simeth, M.; Seifert, R.W. Knowledge spillovers in the supply chain: Evidence from the high tech sectors. Res. Policy 2016, 45, 699-706. [CrossRef]

22. Pierre, D.; Garrette, B.; Mitchell, W. Learning from competing partners: Outcomes and durations of scale and link alliances in Europe, North America and Asia. Strateg. Manag. J. 2000, 21, 99-126.

23. Juliana, H.; Mahnke, V. Outsourcing R\&D: A review, model, and research agenda. R D Manag. 2011, 41, 1-7.

24. Anyan, Q.; Ahn, H.; Sinha, A. Investing in a shared supplier in a competitive market: Stochastic capacity case. Prod. Oper. Manag. 2015, 24, 1537-1551. 
25. Kang, M.P.; Mahoney, J.T.; Tan, D. Why firms make unilateral investments specific to other firms: The case of OEM suppliers. Strateg. Manag. J. 2009, 30, 117-135. [CrossRef]

26. Wang, T.; Wang, J.; Wu, P.; Wang, J.; He, Q.; Wang, X. Estimating the environmental costs and benefits of demolition waste using life cycle assessment and willingness-to-pay: A case study in Shenzhen. J. Clean. Prod. 2018, 172, 14-26. [CrossRef]

27. Hotelling, H. Stability in Competition. Econ. J. 1929, 39, 41-57. [CrossRef]

28. Song, Y.; Tan, Y.; Song, Y.; Wu, P.; Cheng, J.C.; Kim, M.J.; Wang, X. Spatial and temporal variations of spatial population accessibility to public hospitals: A case study of rural-urban comparison. Gisci. Remote Sens. 2018. [CrossRef]

29. Chen, Y.J.; Sheu, J.B. Pursuing extended producer responsibility in the context of EIPs by a Hotelling model. J. Clean. Prod. 2013, 57, 152-157. [CrossRef]

30. Orlov, A. Effects of higher domestic gas prices in Russia on the European gas market: A game theoretical Hotelling model. Appl. Energy 2016, 164, 188-199. [CrossRef]

31. Lijesen, M. Hotelling's webshop. J. Econ. 2013, 109, 193-200. [CrossRef]

32. Liu, Y.; Tyagi, R.K. The benefits of competitive upward channel decentralization. Manag. Sci. 2011, 57, 741-751. [CrossRef]

33. Hara, R.; Matsubayashi, N. Premium store brand: Product development collaboration between retailers and national brand manufacturers. Int. J. Prod. Econ. 2017, 185, 128-138. [CrossRef]

34. D'Aspremont, C.; Gabszewicz, J.J.; Thisse, J.F. On Hotelling's "Stability in competition”. Econ. J. Econ. Soc. 1979, 47, 1145-1150. [CrossRef]

35. Andaluz, J. Vertical product differentiation with subcontracting. Pap. Reg. Sci. 2009, 88, 785-798. [CrossRef]

36. Arya, A.; Mittendorf, B.; Sappington, D.E. Outsourcing, vertical integration, and price vs. quantity competition. Int. J. Ind. Organ. 2008, 26, 1-16. [CrossRef]

(C) 2018 by the authors. Licensee MDPI, Basel, Switzerland. This article is an open access article distributed under the terms and conditions of the Creative Commons Attribution (CC BY) license (http://creativecommons.org/licenses/by/4.0/). 